\title{
Laser Beam Machining - An Overview
}

\author{
Prashant P. Kharche ${ }^{1}$, Dr. Vijay H. Patil ${ }^{2}$ \\ ${ }^{1}$ Research Scholar, Department of Mechanical Engineering, GF's Godavari College of Engineering, Jalgaon, India, \\ ${ }^{2}$ Professor \& Principal, Department of Mechanical Engineering, GF's Godavari College of Engineering, Jalgaon, India,
}

\begin{abstract}
Laser beam machinery (LBM) is one of the most used advanced processes based on thermal energy, which can be used in nearly all kinds of materials. The unwanted material is melted and vaporized from the parent material using a laser beam. It is suitable for cutting and making miniature sheet metal holes in geometrical complexity. $\mathrm{CO} 2$ and Nd: YAG lasers are most widely established among various types of lasers used in industrial machining. Researchers have been exploring various ways of improves the performance of the LBM process in recent years by analyzing the different factors that influence quality. This paper reviews the detailed study of Laser Beam Machining.
\end{abstract}

Keywords-Laser beam machine, Nd:YAG laser, CO2 laser.

\section{I-INTRODUCTION}

T he use of traditional machining technologies is limited due to the emergence of innovative engineering materials, severe design requirements, intricate shape, and unusual size of work piece. As a result, it was decided to design some advanced machining processes (AMPs), which are nonconventional machining procedures. Numerous advanced machining processes (AMPs) are used in today's industry, but each has its own set of constraints in terms of work piece material, shape, and other factors. Advanced machining processes are beam machining processes, jet machining processes, electro discharge machining, electrochemical machining, chemical machining processes, ultrasonic machining (Avanish Kumar Dubey et. al, 2008).

LBM is a cutting technique that is used to shape a wide range of engineering materials. cutting, drilling, marking, welding, sintering and heat treatment are just a few of the applications for laser beams. Although the laser can be used for turning and milling, its major application is in the cutting of metallic and non-metallic sheets. (Avanish Kumar Dubey et. al,2008).

A laser beam with a high energy density provides highly targeted heating on a workpiece in the Laser Beam Machining method. The material is caused to melt, vaporize or ablate in order to remove the material from the piece at micron level. It is an energy-less thermal beam based non-contact tool with several unique advantages, such as a micro-machining potential, elimination of finishing operations, automation adaptability and increased material usage and faster machining (Bijoy Bhattacharyya et. al,2020).

CO2 Laser, Nd:YAG laser, Fiber Laser, Diode Laser, Metal Vapor Deposition Laser and Excimer lasers are used for material machining. Among these, The Nd:YAG laser, for example, has outstanding micromachining properties and a high level of accuracy and surface finish. Laser CO2 has 10640nm of wavelength. The wavelength of a Fiber laser and a Nd:YAG laser in 


\section{International Journal of Innovations in Engineering and Science, www.ijies.net}

the infrared (IR) spectrum is $1064 \mathrm{~nm}$. A gas excimer laser has a wavelength in the ultraviolet (UV) range (Bijoy Bhattacharyya et. al,2020).

\section{LASER BEAM MACHINING (LBM)}

\section{A. Types of Lasers}

Solid State lasers and Gas Lasers are two types of lasers used in machining applications. Nd:YAG lasers, Fiber lasers, Diode lasers, and Ti: Sapphire lasers are the different types of solid state lasers. Solid state lasers are categorized as lamp pumped and diode pumped depending on the type of energy source used for excitation. CO2 Lasers, Excimer Lasers, and Copper Vapor Lasers are the three types of gas lasers used in machining. Lasers are categorized as Continuous Wave (CW) and Pulsed Wave (PW) based on their wave properties (PW) (J.D. Majumdar et. al.,2003; Avanish Kumar Dubey et. al,2008; Mangesh V. Pantawane et. al, 2018).

Because its photons have the same frequency, wavelength, and phase as regular light, laser light is distinguished from ordinary light. As a result, laser beams, unlike regular light, are extremely directed, have a high power density, and have improved focusing capabilities. The specific features of a laser beam are important in material processing. Nd:YAG and $\mathrm{CO} 2$ lasers are the most commonly utilized for LBM among the various types of lasers. In infrared region, $\mathrm{CO} 2$ lasers have a wavelength of $10 \mathrm{~mm}$. Its beam power is very high, its efficiency is better and the beam is good quality. It can be used for high-speed fine sheet metal cutting. (T. Norikazu et. al,1996; Avanish Kumar Dubey et. al,2008).

Although Nd:YAG lasers have a modest beam power, when used in pulsed mode, they can process even thicker materials. Shorter pulse durations are also better for cutting thinner materials. It can be absorbed by high reflective materials that are difficult to process with $\mathrm{CO} 2$ lasers due to its lower wavelength $(1 \mathrm{~mm})$ (J. Meijer,2004; Avanish Kumar Dubey et. al,2008).

\section{B. Principle of LBM}

Melting, vaporization, and chemical degradation are all stages of the material removal mechanism during LBM. When a laser beam with a high energy density is focused on the work surface, the work volume is heated and transformed into a molten, vaporized, or chemically altered state as the thermal energy is absorbed, that can be easily removed with the help of a high-pressure assist gas jet (Avanish Kumar Dubey et. al,2008).

The LBM process is a thermal one. Thermal properties have an impact on the efficiency of this procedure and to a certain extent, rather than the mechanical properties of the material to be machined, consider its optical properties. Materials that show a high amount of brittleness or hardness and that have advantageous thermal properties, particularly suitable for laser machining, such as low thermal diffusivity and conductivity.

Because irradiation is used to transfer energy from the laser to the material, the laser doesn't provide any cutting forces, as a result, mechanically induced material degradation, tool wear, and machine vibration are eliminated. Furthermore, for laser machining, there are no limits such as maximum tool force, built-up edge creation, or tool chatter that limit the material removal rate (MRR). LBM is a process that allows for a lot of flexibility. The laser beam can be utilized for drilling, cutting, grooving, welding, and heat treating procedures on a single machine when paired with a multi-axis workpiece positioning system or robot (D.T. Pham et.al,2007).

\section{LBM variations}

Drilling (1-D), cutting (2-D) and grooving, turning and milling (3-D), and micromachining of various workpiece materials are the most common LBM configurations. For drilling hundreds of closely spaced holes in structures, laser beam drilling has become the acknowledged and cost-effective method. Trepan and percussion laser beam drilling are two forms of laser beam drilling. Trepan drilling entails cutting all the way around the hole's circumference, with no relative movement of the laser or workpiece, percussive drilling 'punches' directly through the workpiece material. The reduction in processing time is a natural benefit of the laser percussion drilling method (G. Chryssolouris,1991; Avanish Kumar Dubey et. al,2008).

Metals, ceramics, and polymers have all been punched, cut-off, and marked using laser beam cutting and grooving processes. Because of the material versatility, no wear or change of tool, high material utilization and production flexibility and high accuracy and edge quality, laser beam cutting is superior to any other cutting technology, conventional or unconventional (Avanish Kumar Dubey et. al,2008). 


\section{International Journal of Innovations in Engineering and Science, www.ijies.net}

Laser beam turning and milling operation are 3D operations and require the desired profile to be achieved by two simultaneous laser beams. With the help of fiber optics, the beams can be focused at the desired angles.

Without the need for expensive tools, laser milling enables for the manufacturing of parts with complex shapes. Laser milling is best suited for one-sided geometry processing parts or partial processing of components of just one side. It is also possible to complete laser milling of parts, but it is difficult to correctly reposition the part of your workplace (D.T. Pham et.al,2007).

\section{II- LASER BEAM MACHINING SYSTEMS DETAILS}

\section{Technology Overview}

Laser machining removes material from a workpiece by localized melt shearing and vaporization, using the energy from an intense, highly directional coherent beam of infrared light. The underlying concept for the formation of all forms of lasers is called LASER, which stands for Light Amplification by Stimulated Emission of Radiation. According to this principle, a photon is produced when an atom or molecule is boosted to a high energy level by an external energy source and then allowed to decay down to its ground state energy level. If that photon contains an energy-efficient atom or molecule, the second atom or molecule shall return to its ground condition and release a second photon together with the triggering photon. The wavelength, phase, direction, and energy (coherent) of the two photons released are identical. Two extremely parallel and partially transmitting mirrors in a laser producing device reflect the generated photons many times. By stimulating the lasing media, the light can be magnified significantly. The light then emerges as a highly converged and coherent beam from the partially transmitting mirror.

Based on the lasing media, lasers are classified as solidstate or gas lasers, as illustrated in Table 3.1. Continuous (CW) and pulsed modes are the two temporal modes in which all lasers operate. The laser beam is continuously emitted in continuous mode. The laser beam is periodically emitted in pulsed mode. The $\mathrm{CO} 2$ lasers can deliver up to $3 \mathrm{~kW}$ of high power, and non-metallic radiation is well absorbed. With an average power of $400 \mathrm{~W}$, the YAG lasers are operated in the solid-state mode and can reach a top power of $7-10 \mathrm{~kW}$. The radiation from the organic materials or glass is not efficiently absorbed. As a result, $\mathrm{CO} 2$ lasers are better for machining composite materials, but YAG lasers are ineffective for cutting glass FRPs (Sheikh-Ahmad J.,2009),

Table 3.1- Type of Lasers used in Machining Application

\begin{tabular}{|l|l|l|}
\hline $\begin{array}{l}\text { Type of } \\
\text { laser }\end{array}$ & Laser material & Wavelength \\
\hline $\begin{array}{l}\text { Solid state } \\
\text { laser }\end{array}$ & $\begin{array}{l}\text { Nd:YAG } \\
\text { (second harmonic) }\end{array}$ & $532 \mathrm{~nm}$ \\
\hline & $\begin{array}{l}\text { Nd:YAG } \\
\text { (third harmonic) }\end{array}$ & $355 \mathrm{~nm}$ \\
\hline & $\begin{array}{l}\text { Nd:YAG } \\
\text { (forth harmonic) }\end{array}$ & $266 \mathrm{~nm}$ \\
\hline Gas laser & Fiber lasers & $1064 \mathrm{~nm}$ \\
\hline & Heliem-neon & $633 \mathrm{~nm}$ \\
\hline
\end{tabular}

1) Laser Cutting Systems Laser cutting systems are made up of four main parts: laser beam generation ( $\mathrm{CO} 2$ or $\mathrm{Nd}: \mathrm{YAG})$; beam delivery and focusing; workpiece positioning relative to the laser beam; and auxiliary devices such as gas nozzle and safety equipment. The laser cutting mechanism is depicted in Figure 3.1. There are several variations of the laser beam introduction to the workpiece. A CNCcontrolled two-axes table could be used to move the workpiece while the beam is fixed. The workpiece is fixed while the beam moves in three-dimensional space in other configurations, such as a robotic arm.A beam delivery system transports and focuses the laser beam for cutting or drilling in all laser systems. Reflecting mirrors, a focusing lens, and a coaxial gas nozzle are all part of the beam delivery system. The beam is focused at an area of $0.1 \mathrm{~mm}$ in diameter and $10 \mathrm{MW} / \mathrm{cm} 2$ in intensity. By providing a secondary heat source, the gas jet passing through the nozzle supports the laser beam in cutting. Heat transfer to the backside of the workpiece is enabled by the gas jet flowing through the kerf at low cutting rates. The gas provides an efficient cooling system on the beam entrance side at high jet pressures and reduces the beam entry kerf width. The assist gas also helps in the mechanical removal of material from the kerf and in keeping debris from contaminating the focusing lens (Fig. 3.2). 


\section{International Journal of Innovations in Engineering and Science, www.ijies.net}

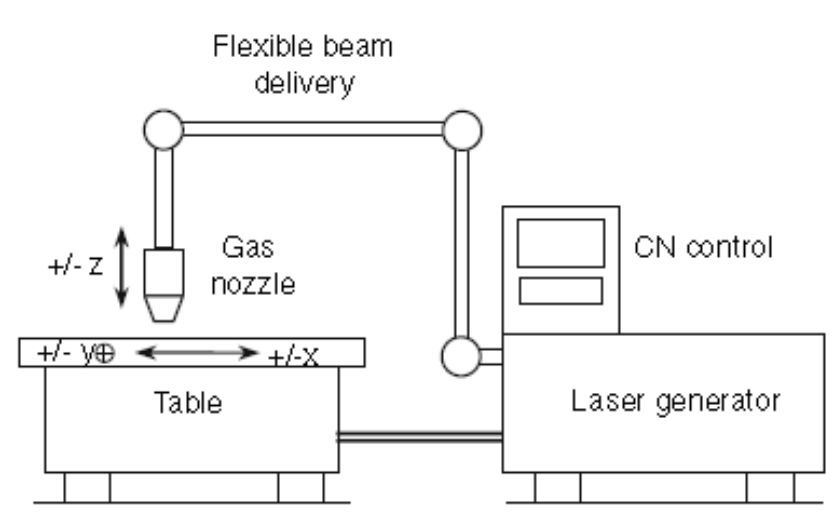

Fig 3.1- Schematic of 3-Axes Laser Cutting System

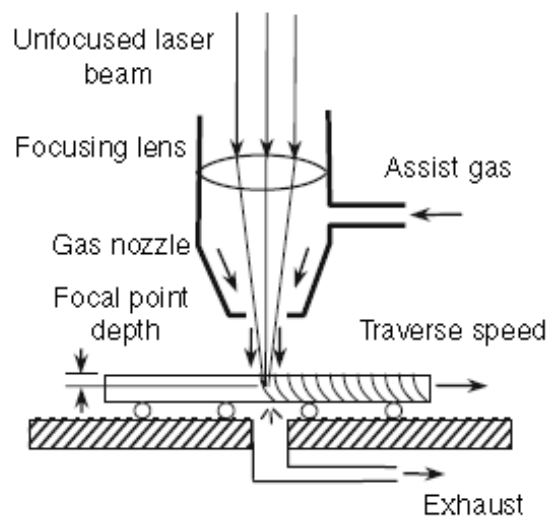

Fig 3.2: Cutaway of the Gas Nozzle

\section{2) Laser Cutting Process Parameters}

The parameters of the laser cutting process are divided into four categories:

a. Laser beam parameters: power density, wavelength of emission, temporal mode ( $\mathrm{CW}$ or pulsed), spatial mode (TEM mode), and focal spot size.

b. Gas parameters: gas mixtures, gas pressure, and nozzle configuration.

c. Machine tool parameters: cutting speed (also known as feed or traverse speed).

d. Workpiece parameters: thickness, absorption coefficient of at the given laser beam wavelength, melting and vaporization heat, melting and vaporization temperatures, thermal conductivity, and heat capacity.

The effectiveness of laser machining is determined by laser parameters and workpiece parameters. The TEM mode (transverse electromagnetic mode) describes and determines how the Laser Beam propagates and focuses in its characteristic spatial pattern. In each of two orthogonal directions, the subscripts "mm" refer to the numbers of nulls of the spatial model that are transverse to the direction of the spreading beam. For machining, the TEM00 mode is often used. In this mode, the intensity of the laser beam is followed as a spot radius by a Gaussian distribution. For gas lasers, the smallest possible spot size is $0.1 \mathrm{~mm}$ in diameter. The workpiece surface reflects part of the incident beam.

The number of reflections on the beam vary in terms of the beam's wavelength and the surface condition of the part. In general, the higher the laser beam wavelength, the greater the surface reflection. The surface of the workpiece absorbs laser energy that is not reflected. Two ways of energy transmission to the workpiece: at low values of specific power, absorption typically takes place in a superficial layer of the material less than $1 \mu \mathrm{m}$ deep and it penetrates further into the material by conduction; high enough to vaporize the material at particular powers, the melted material forms a vapour column around it. More efficient heat transmission happens as a result of the many reflections of the beam within the hole and the energy absorbed across the full thickness of the workpiece. Specific powers of $102-103 \mathrm{~W} / \mathrm{cm} 2$ are required for deep penetration in composite materials. The laser beam diameter, assist gas pressure, absorption coefficient, and material vaporization temperature all influence the size of the hole and heat transmission efficiency. (Ahmad, 2009).

\section{III -MATERIAL REMOVAL MECHANISM IN LASER BEAM MACHINING}

After passing through a lens, the powered laser beam is focussed to a point. As a result, there is a significant concentration of energy at that point. The optical energy is transformed to heat once laser radiation is absorbed by the material surface. The wavelength of the laser, its temperature, the reflectivity of the work piece, the angle of incidence of the laser beam on the work piece, and the intensity of the focussed laser beam all influence the amount of laser radiation absorbed by the work piece. The material melts and vaporises as a result of the tremendous heat. A significant mechanical impulse is generated to remove a big amount of molten material from the cutting zone because a portion of the material vaporises so quickly. Laser ablation is a phenomenon that occurs when a short pulse laser is used. Ceramic materials suffer from thermal spalling. A very high speed, additional assist gas jet is used that pushes the material leading to the expulsion. 


\section{International Journal of Innovations in Engineering and Science, www.ijies.net}

Various effects of laser material interactions are observed in figure 4.1, during the removal of materials from laser beam processes, including heating, surface melting, vaporization, plasma formation and removal and deposition. During the use of long laser pulse beams during processing, thermal effects occur during the material removal process, as shown in the Fig. 4.2, like formation of the melting zone, heat- affected zone, recast layer, thermal damages of the adjoining layers etc.

However, while a material is removed without melting while making short pulse or ultra short pulse laser beams, there is no thermal damage during material removal. There are changes of states such as heating of room temperature to melting point, melting, heating of melt to vaporization temperature and then vaporization of molten materials, when laser beam is incident on the surface of the materials.

For these changes, the required energy $(\mathrm{E})$ is given as:

$$
E=m[C p(T m-T r)+L m+C p(T m-T v)+
$$
$L v] / A t \quad$ (1)

where $\mathrm{E}=$ the amount of energy required by a laser beam to remove a material mass $(\mathrm{m})$; $\mathrm{Cp}$ is a material's specific heat; $\operatorname{Tr}$ is the the materials' room temperature $\mathrm{Tm}$ and $\mathrm{Tv}$ are melting point and vaporization point temperature respectively. $\mathrm{Lm}$ and $\mathrm{Lv}$ are latent heat of melting and vaporization respectively. The machining time is represented as $t$. The percentage of incident energy absorbed is represented as A.

The mass of material removed per unit time (MRR) can be calculated using the energy balance equation:

$$
\begin{aligned}
M R R= & \frac{m}{t}=E A /[C p(T m-T r)+L m \\
& +C p(T m-T v)+L v]
\end{aligned}
$$

During laser cutting of a slot of width, w, and depth, d of material with density $\mathrm{p}$, the machining speed $(\mathrm{V})$ is represented as:

$$
\begin{gathered}
V=\frac{m}{w \cdot d \cdot p \cdot t}=E A /[C p(T m-T r)+L m+C p(T m \\
-T v)+L v] w \cdot d \cdot p
\end{gathered}
$$

(3)

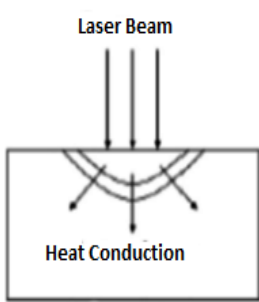

(a) Heating

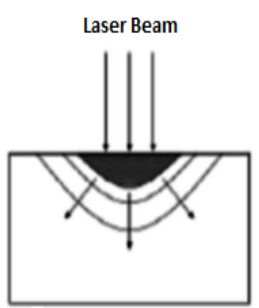

(b) Surface Melting

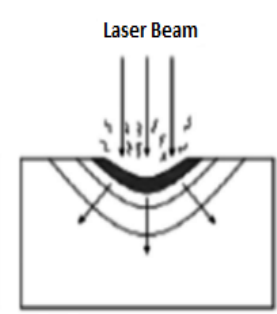

(c) Surface Vaporization

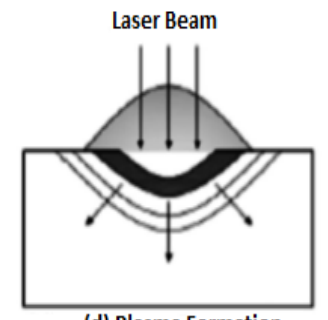

(d) Plasma Formation

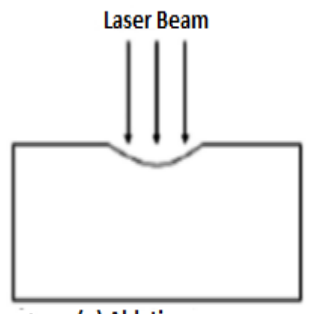

(e) Ablation
Fig 4.1-Various Effects Of Laser Material Interactions Such As (A) Heating, (B) Surface Melting, (C) Vaporization, (D) Plasma Formation And (E) Ablation (Chryssolouris G. et. al.,2013).

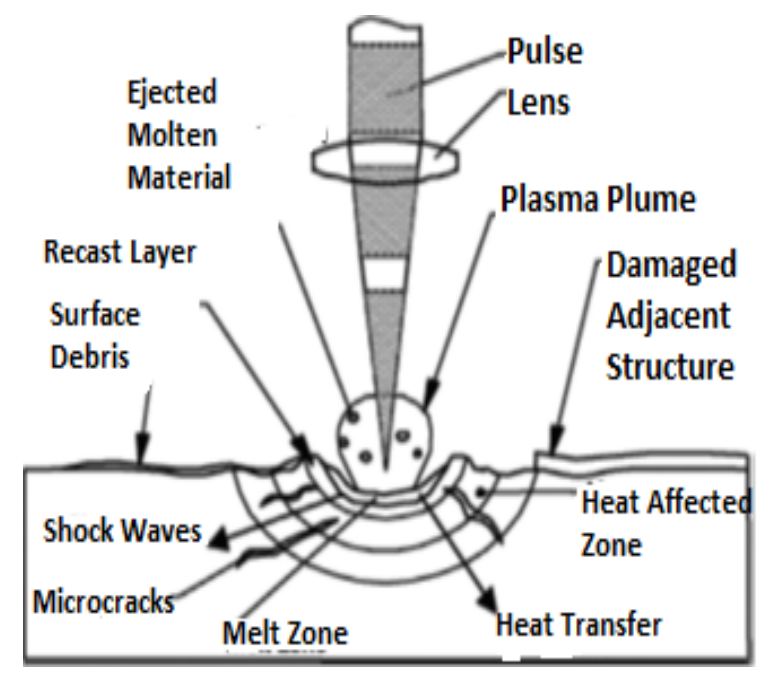

Fig 4.2- Schematic Representations Of Thermal Effects Of Long Pulse Laser Material Interactions (J.F. Ready et. al,2001).

\section{Advantages and Limitations of Laser Beam Machining Processes}

\section{A. Advantages}

For a variety of industrial applications, laser beam machining can replace traditional machining procedures because of the advantages listed below.

(a) LBM can generate a superior finished machining surface, eliminating the need for post-processing.

(b) For machining hazardous materials such as nuclear fuel rods, a laser beam can be delivered to a remote location.

(c) By concentrating the beam, LBM may remove materials from specific areas of the workpiece.

(d) It is a clean machining process because no solvents or chemicals are utilised during the machining process.

(e) For high productivity and high speed machining, LBM offers the ability to adapt to automation. 


\section{International Journal of Innovations in Engineering and Science, www.ijies.net}

(f) LBM is a sort of non-contact processing and there is no physical tool. As a result, there is no tool wear or machining force. Machine components are free of mechanically induced material deterioration and vibration.

(g) Lasers can quickly cut complex profiles with a high degree of accuracy.

(h) The thermal and, to some extent, optical qualities of the material to be machined are more important than mechanical features in the laser beam machining process. As a result, any material, regardless of brittleness or hardness, can be machined. Laser machining works best with materials with low thermal diffusivity and conductivity.

(i) Laser beam machining is not affected by the workpiece's electrical conductivity. It can work with a wide range of materials, including polymers and diamonds.

(j) Laser processing of materials is extremely quick, resulting in a very small heat affected zone (HAZ).

(k) Micro-features with large aspect ratio and acceptable accuracy and dimensions can be generated.

(1) Less removal of material from selected parts of the material is removed in LBM.

It therefore reduces waste.

(m) Laser beam machining, when combined with multiaxis positioning system or robot, is highly flexible machining system. Therefore, the automation can be adapted for LBM.

(n) Drilling, cutting, grooving, scribing, marking, cleaning, and turning are just a few of the material processing techniques available with laser beam machining.

\section{B. Limitations}

There are several limitations to laser beam micro machining because it is a thermal material removal method. Limitations are:

(a) Initial investment costs are high.

(b) LBM system maintenance is costly and requires skilled operators to perform various operations.

(c) The efficiency of the input electrical energy to the LBM machine is low compared with the laser beam power. However, different industrial laser's development and research concerns may improve the efficiency of converting electrical energy to beam energy. (d) Laser beams cannot process highly reflecting and transparent materials in the machining condition.

(e) For heavier materials, it has limited applicability, but it is ideal for smaller cross-sectional materials.

(f) The rate of metal removal is really low.

\section{IV-CONCLUSION}

Laser beam machining is a widely used nonconventional manufacturing process. It is based on thermal, noncontact interaction between a beam and the material to be machined. It can be applied to a wide range of materials. This paper gives the details of Laser Beam Machining, its overview of technology, material removal mechanism, advantages and limitations.

\section{REFERENCES}

[1] Avanish Kumar Dubey, Vinod Yadava (2008). Laser beam machining - A review, International Journal of Machine Tools and Manufacture, Volume 48, Issue 6, Pages 609-628, ISSN 0890-6955.

[2] Bijoy Bhattacharyya, BiswanathDoloi (2020). 2020 Chapter Four - Machining processes utilizing thermal energy, Editor(s): Bijoy Bhattacharyya, BiswanathDoloi, Modern Machining Technology, Academic Press, Pages 161-363, ISBN 9780128128947.

[3] Chryssolouris G., Stavropoulos P., Salonitis K. (2013) Process of Laser Machining. In: Nee A. (eds) Handbook of Manufacturing Engineering and Technology. Springer, London. https://doi.org/10.1007/978-1-4471-4976-7_74-2

[4] D.T. Pham, S.S. Dimov, P.T. Petkov (2007). Laser milling of ceramic components, International Journal of Machine Tools and Manufacture 47, 618626.

[5] G. . Chryssolouris (1991), Laser Machining-Theory and Practice. Mechanical Engineering Series, Springer-Verlag, New York Inc., New York.

[6] J.D. Majumdar, I. Manna (2003). Laser processing of materials, Sadhana Vol. 28 Parts (3-4) pp.495562.

[7] J.F. Ready, D.F. Farson (2001). Hand Book of Laser Materials Processing, LIA Magnolia Publishing Inc., USA.

[8] J. Meijer (2004). Laser beam machining (LBM), state of the art and new opportunities, Journal of Materials Processing Technology 149, 2-17.

[9] Mangesh V. Pantawane, Sameehan S. Joshi, and Narendra B. Dahotre (2018). Laser Beam Machining of Aluminum and Aluminum Alloys, ASM Handbook, Volume 2A, Aluminum Science and Technology Kevin Anderson, John Weritz, and J. Gilbert Kaufman, editors. 
Vol. 6, No. 10, 2021, PP. 168-174

International Journal of Innovations in Engineering and Science, www.ijies.net

[10] Sheikh-Ahmad J (2009). - Machining of Polymer Composites, Springer Science + Business Media, Germany.

[11] T. Norikazu, Y. Shigenori, H. Masao (1996). Present and future of lasers for fine cutting of metal plate, Journal of Materials Processing Technology 62, 309-314. 